\title{
Redesign Instalasi Sistem Pendingin Bearing Turbine PLTA Tanggari untuk Mengubah Pola Maintenance dari Offline Menjadi Online
}

\author{
Meyer Nixon Nelwan ${ }^{1}$; Salman ${ }^{2}$ \\ ${ }^{1}$ PUSDIKLAT, UPDL Makassar \\ ${ }^{2}$ UIKL Sulawesi, ULPLTA Tanggari \\ ${ }^{1}$ meyer.nelwan@gmail.com \\ ${ }^{2}$ salman.pln@pln.co.id
}

\begin{abstract}
Hydroelectric power plant is one of the power plants that uses renewable energy sources with a low cost of production, in addition to providing a large enough profit for PLN, it can also be a source of revenue to cover production costs in meeting the system needs, so that the hydropower continues to operate optimally, Currently the Tanggari Hydroelectric Power Plant's special operating pattern can be approved not yet maximally based on the number of maintenance hours reaching 3-5 hours I month, this causes potential losses because most jam hours are carried out during the rainy season Turbine bearing temperature conditions continue to increase considering the poor air conditions associated special problem for hydropower. In this journal the author brings one of the breakthrough ideas to overcome this by implementing the Redesign of the Hydro Turbine Cooling System Installation to facilitate backwashing so that it can change maintenance patterns from offline to online. Implementation results can provide benefits because hydropower no longer needs to perform maintenance on the cooling system with offline mode so that hydropower can operate more optimally.
\end{abstract}

Keywords: PLTA, Redesign, Backwash, Bearing turbin, Online

\begin{abstract}
ABSTRAK
PLTA merupakan salah satu pembangkit listrik yang menggunakan sumber energi terbarukan dengan biaya pokok produksi yang rendah, selain memberikan keuntungan cukup besar bagi PLN juga bisa menjadi salah satu sumber pendapatan untuk menutup biaya produksi pembangkit lain yang masih menggunakan BBM dalam membangkitkan listrik, mengingat pentingnya peran PLTA dalam memenuhi kebutuhan system maka perlu menjaga agar PLTA tetap beroperasi dengan maksimal, saat ini pola operasi khususnya unit PLTA Tanggari bisa dikatakan belum maksimal dikarenakan jumlah jam pemeliharaan mencapai 3-5 jam/bulan, ini menyebabkan potensi kerugian karena sebagian besar jam pemeliharaan dilakukan saat musim hujan. Kondisi suhu bearing turbin yang terus mengalami kenaikan dikarenakan kondisi air yang buruk menjadi masalah tersendiri bagi PLTA. Pada jurnal ini penulis membawa salah satu ide terobosan untuk mengatasi hal tersebut dengan melaksanakan Redesign Instalasi Sistem Pendingin Bearing Turbine PLTA untuk memfasilitasi melakukan backwash sehingga bisa mengubah pola maintenance dari offline menjadi online. Hasil implementasi dapat memberikan keuntungan dikarenakan PLTA tidak perlu lagi melakukan pemeliharaan pada sistem pendingin dengan mode offline sehingga PLTA bisa beroperasi lebih maksimal.
\end{abstract}

Kata kunci: PLTA, Redesign, Backwash, Bearing turbin, Online

80 | Energi dan Kelistrikan: Jurnal Ilmiah 


\section{PENDAHULUAN}

Indonesia memiliki potensi tenaga air yang tersebar diseluruh daerah $\pm 75.000 \mathrm{MW}$.[1] PLTA merupakan salah satu renewable energy yang murah dan ramah lingkungan dalam pengoperasiannya, dimana pengoperasian PLTA dengan memanfaatkan sumber daya air yang ditampung pada reservoir yang selanjutnya disalurkan melalui pipa pesat sehingga kecepatan air yang disalurkan melalui pipa pesat bisa memutar turbin air, dikarenakan turbin air yang terhubung dengan poros generator menyebabkan rotor generator ikut berputar sehingga antara rotor dan stator terjadi perubahan medan magnet, dari perubahan medan magnet maka terjadilah GGL.[2] Dalam pengoperasian PLTA ada beberapa hal yang harus diperhatikan adalah terkait pemeliharaannya. Salah satu tantangan yang menjadi perhatian penulis dalam mengembangkan riset ini adalah mengenai kesiapan pembangkit PLTA Tanggari, dimana selama ini pembangkit selalu melakukan pemeliharaan yang mengharuskan unit untuk shutdown. Pemeliharaan tersebut mengakibatkan hilangnya potensi daya yang dapat disalurkan ke sistem 70kV. Unit pembangkit selama ini memiliki masalah dalam sistem pendinginan, dimana pelaksanaan pembersihan pada cooler-cooler harus dilakukan setiap bulannya. Adapun pada musim penghujan pelaksanaan pemeliharaan menjadi lebih sering dibanding musim kemarau, hal tersebut dikarenakan kondisi air yang menjadi lebih keruh diakibatkan oleh material sungai yang terbawa arus.

Kondisi PLTA Tanggari memiliki alur sistem pendingin dimana air sistem pendingin diambil dari tailrace, Air dari tailrace akan dipompa-kan menuju headtank, setelah ditampung dikirimkan menuju strainer, Strainer berfungsi sebagai saringan/pembersihan pada sistem air pendingin sebelum dialirkan menuju pipa-pipa pendingin. Air yang digunakan berasal dari tail race yang merupakan buangan dari operasi pembangkit, kondisi air yang mengandung lumpur juga menjadi salah satu kendala dalam sistem pendinginan. Air pendingin yang telah melewati strainer dikirimkan melalui motor valve dan distribusikan menuju cooler-cooler yang berfungsi untuk mendinginkan radiator, heat exchanger thrust dan upper bearing, lower bearing dan turbine bearing. Kondisi pendingin bearing diantaranya thrust, upper bearing dan lower bearing menggunakan sistem heat exchanger dengan tipe plat, khusus untuk turbine bearing sistem pendinginnya menggunakan pendingin yang dicelupkan (circular one piece). Untuk pemeliharaannya pendingin dengan tipe plat lebih mudah karena kondisinya redundant sehingga dapat dialihkan walaupun pembangkit sementara beroperasi. Sementara itu untuk membersihkan sistem pendingin pada turbine bearing cukup rumit karena apabila akan dilakukan pembersihan pendingin tidak dapat dikeluarkan dari tangki turbine bearing. Untuk pelaksanaan pemeliharaan pembersihan turbine bearing, cover tangki bearing, dudukan turbine bearing dan untuk melakukan hal tersebut membutuhkan waktu hingga 3-5 jam/bulan. Sehingga hal tersebut tidak efektif untuk dilaksanakan selain memakan waktu lama kesulitan saat pembongkaran dan pemasangan dapat mengakibatkan gangguan lainnya. Alternatif lainnya adalah pembersihan dengan metoda backwash namun kondisi saat ini tidak terpasang fasilitas untuk backwash sehingga pelaksanaan pemeliharaan harus menunggu unit shutdown.

\section{METODE/PERANCANGAN PENELITIAN}

Lokasi penelitian dilakukan di PLTA Tanggari.[3] Metode yang digunakan untuk menyelesaikan permasalahan terkait sistem pendingin diantaranya, dengan melakukan studi literature terkait pengumpulan informasi atau teori-teori pendukung yang masih relevan, setelah itu melakukan identifikasi dengan melakukan perumusan dari latar belakang sampai tujuan melakukan penelitian, melakukan observasi dengan melakukan pengamatan pada system pendingin yang ada pada PLTA Tanggari, selanjutnya melakukan analisa untuk penyelesaian permasalahan, adapun hal- 
hal yang diamati terkait temperature pada oil bearing turbin yang tinggi dan system pendinginan pada oil bearing turbine

Setelah dilakukan analisa terkait masalah yang ada, maka didapatlah masalah utamanya yaitu fungsi pendingin yang tidak berfungsi dengan baik dikarenakan endapan lumpur yang masuk pada jalur pipa pendingin, untuk mengatasi umpur yang masuk pada pia pendingin maka dilakuakan pembersihan pada pipa pendingin (backwash) tanpa melakukan shutdown pada mesin pembangkit. Untuk perencanaan pipa clearing secara online bias dilihat pada gambar 1.

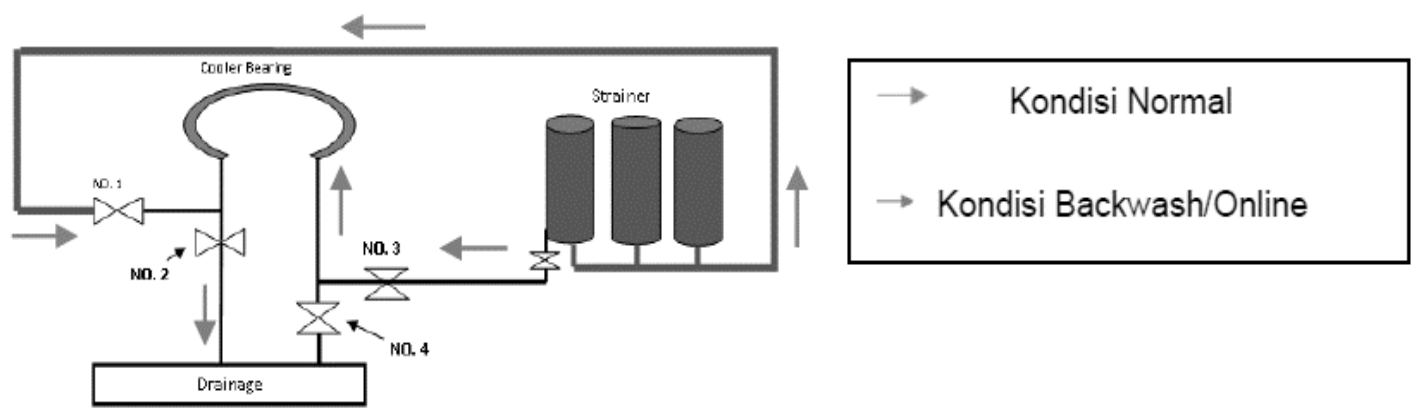

Gambar 1. Alur pipa cleaning online

\section{HASIL DAN PEMBAHASAN}

\section{Sistem Backwash}

Konsep yang dipergunakan mengacu pada sistem backwash pada kondenser yang terdapat di PLTU. Konsep tersebut diambil dari peralatan kondensor pada PLTU yang mana kondensor berfungsi sebagai alat penukar kalor yang berfungsi mengkondensasikan uap bekas turbin menjadi titik-titik air dan uap yang terkondensasi menjadi air yang ditampung pada Hotwell. Prinsip kerja kondensor dimana air laut mengalir di dalam tube untuk mendinginkan uap bekas yang berasal dari last stage steam turbine. Prinsip kerja kondensor juga digunakan pada sistem pendingin bearing turbine dimana air pendingin mengalir di dalam tube untuk mendinginkan oli pada bearing turbine.

Selain pada prinsip kerjanya beberapa masalah yang terjadi pada sistem kondensor dan sistem pendingin turbine bearing mengalami masalah yang hampir serupa. Masalah tersebut adalah terjadinya fouling pada sistem pendingin. Fouling atau endapan sangat mungkin terjadi pada sistem pendingin, endapan lumpur atau tritip (PLTU) mengotori tube-tube sistem pendingin ini berasal dari sumber pengambilan bahan baku air pendingin. Pada umumnya pengambilan air pada PLTU berasal dari laut dan kemungkinan besar mengandung endapan kotoran dan binatang laut yang ikut masuk dan mengendap pada tube-tube sistem pendingin, hal ini dapat menyebabkan menurunnya laju perpindahan panas pada kondensor. Hal tersebut juga berlaku pada sistem pendingin PLTA khususnya pada sistem pendingin bearing yang menggunakan tipe pendingin celup (circular one piece). Kondisi air pendingin yang mengandung endapan lumpur juga akan menyebabkan penurunan laju perpindahan panas pada sistem pendingin.

Terdapat dua cara pembersihan untuk mengurangi fouling dan meningkatkan perpindahan panas pada sistem pendingin yang telah diterapkan pada PLTU, diantaranya backwash dan ball cleaning. Backwash yaitu proses pembersihan sistem pendingin dari kotoran yang menyumbat dan menggangu proses aliran air pendingin dengan cara membalik arah alirannya. Kondisi sistem kondensor pada PLTU didesain dengan dua sisi yang arah alirannya berlawanan, proses ini dilakukan dengan membalikan arah inlet dan outlet. Hal ini dapat dilakukan juga pada sistem pendingin bearing pada PLTA, air yang masuk melalui inlet sistem pendingin yang dicelupkan pada sistem pelumas 
dapat dibalikkan menjadi outletnya. Sehingga pelaksanaan pembersihan dengan sistem backwash menjadi relevan pada kondisi pendigin bearing PLTA. [4]
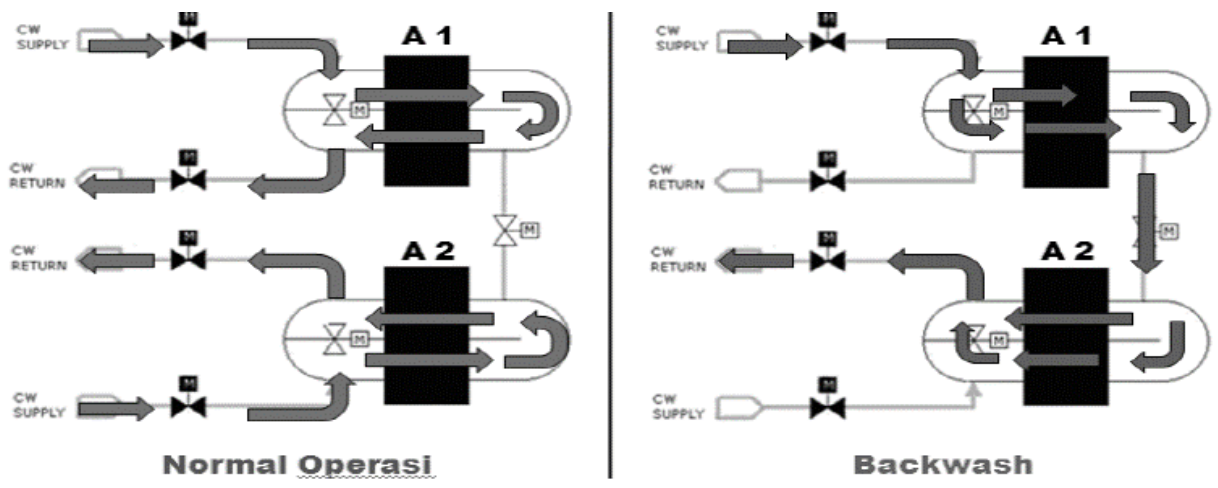

Gambar 2. Aliran air dengan operasi normal dan system backwash pada PLTU[5]

Tabel 1. Urutan Instalasi Sistem Backwash

\begin{tabular}{|l|l|l|}
\hline Kondisi buangan cooler sebelum \\
dilakukan redesign system pendingin
\end{tabular}






Setelah semua pelaksanaan perencanaan dan pemasangan selesai, dilakukan pelaksanaan pengujian dengan mengalirkan air melalui jalur-jalur pipa tersebut, pengujian ini bertujuan untuk memastikan tidak terjadi passing/kebocoran pada jalur pipa yang digunakan, setelah dipastikan peralatan aman dan tidak ada kebocoran maka dilaksanakan cleaning online dan closingnya. Dengan melakukan redesign instalasi sistem pendingin pada PLTA Tanggari maka didapatkan hasil sebagai berikut:

1. Waktu pemeliharaan

Semula harus melakukan shutdown pada mesin pembangkit selama waktu 3-5 jam/bulan untuk melakukan pemeliharaan namun setelah melakukan redesign pada system pendingin maka tidak lagi dilakukan shutdown mesin untuk melakukan pemeliharaan pada system pendingin.

2. Terjadi penurunan suhu pada Bearing Turbine

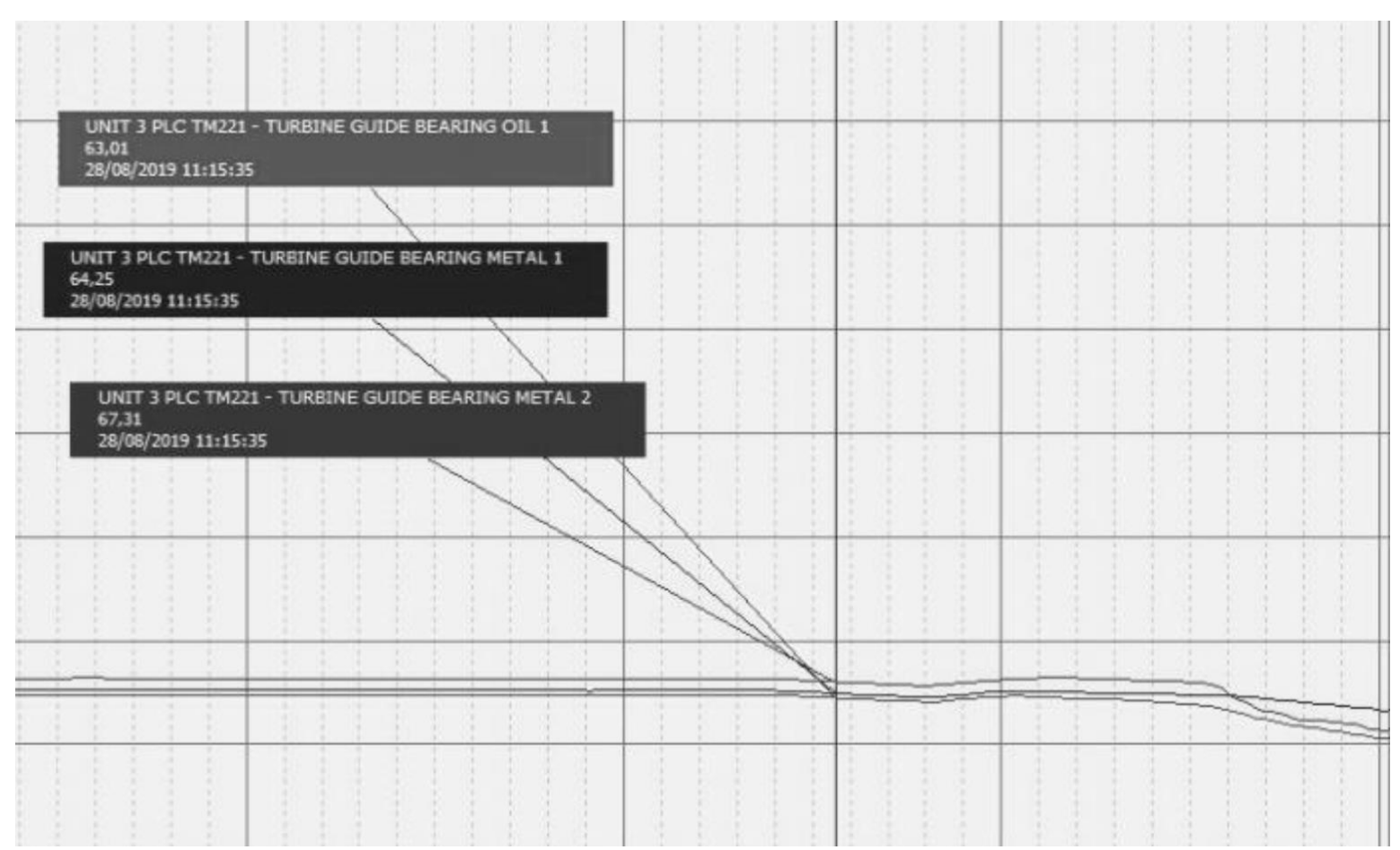

Gambar 3. Trend Sebelum Pengujian

Gambar 3 menunjukan trend suhu sebelum dilakukan pengujian dimana rincian nilai suhunya sebagai berikut:

1. Turbine Guide Bearing Metal 1: $64.25^{\circ} \mathrm{C}$,

2. Turbine Guide Bearing Metal 2: $67.11^{\circ} \mathrm{C}$

3. Turbine Guide Bearing Oil 1: $63.01^{\circ} \mathrm{C}$ 


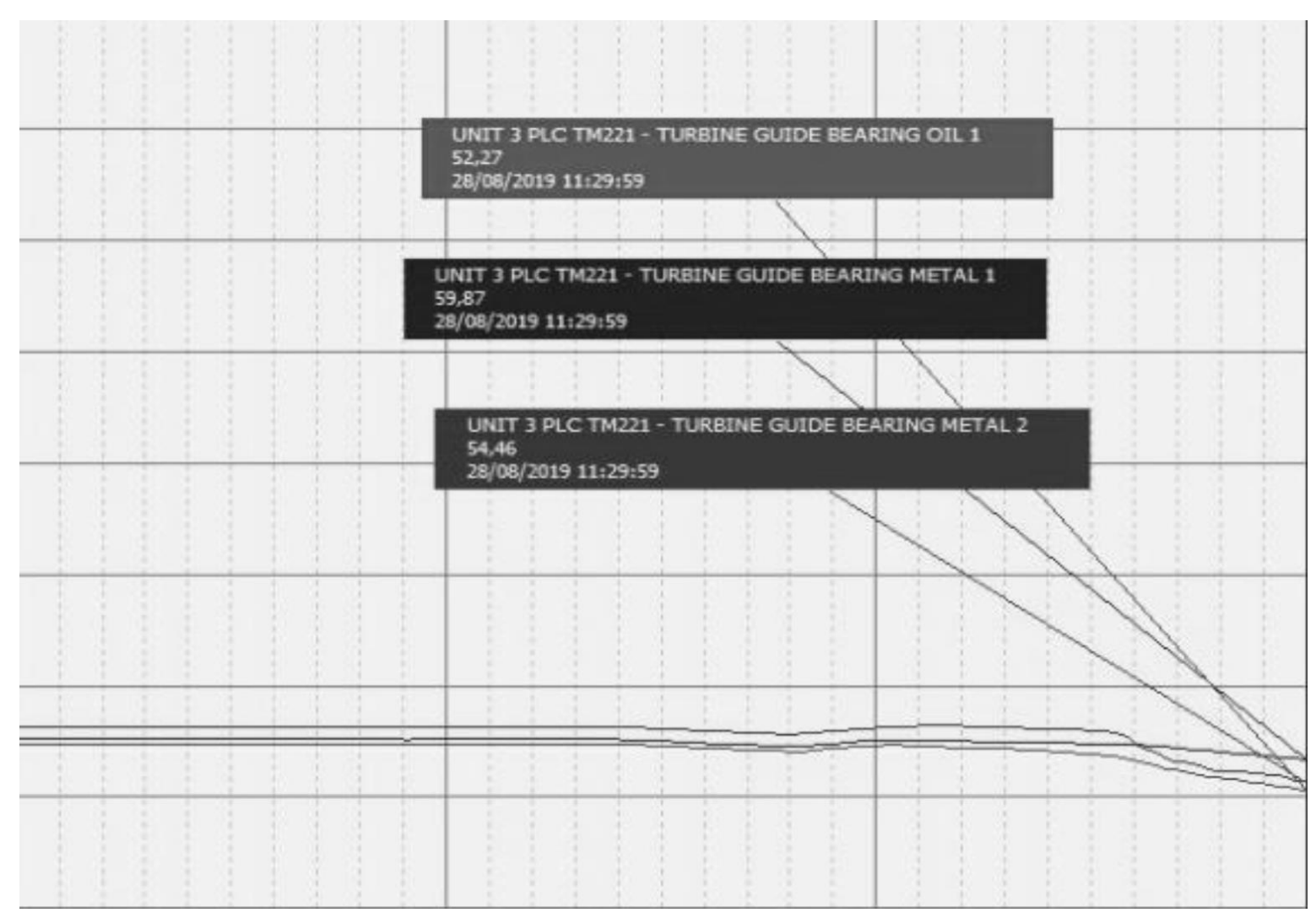

Gambar 4. Trend Setelah Pengujian

Gambar 4 menunjukan trend suhu setelah dilakukan pengujian dimana rincian nilai suhunya sebagai berikut:

1. Turbine Guide Bearing Metal $1: 59.87^{\circ} \mathrm{C}$

2. Turbine Guide Bearing Metal 2: $54.46^{\circ} \mathrm{C}$

3. Turbine Guide Bearing Oil: $52.27^{\circ} \mathrm{C}$

\section{KESIMPULAN DAN SARAN}

Penerapan system backwash melalui pelaksanaan redesign instalasi sistem pendingin bearing turbine memberikan hasil yang baik, dimana pada pengujian online yang dilakukan diperoleh data terkait penurunan waktu pelaksanaan pemeliharaan dari 3-5 jam/bulan menjadi 0 jam/bulan untuk pelaksanaan pemeliharaan system pendingin bearing turbine, selain terjadi penurunan waktu dalam pemeliharaan pada bearing turbin juga mengalami penurunan suhu.

Merekomendasikan agar redesign system pendingin bisa diterapkan pada unit PLTA yang lain agar bisa mengurangi jumlah shutdown mesin pembangkit dikarenakan adanya pemeliharaan pada system pendingin.

\section{DAFTAR PUSTAKA}

[1] Badaruddin and J. P. Suwarjono, "STUDI ANALISA PEMBANGKIT LISTRIK TENAGA AIR ALTERNATIVE MICROHYDRO Badaruddin 1, Jonathan Pedro Suwarjono 2," Tek. Elektro, vol. 4, no. 3, pp. 100-108, 2013.

[2] H. Prasetijo and G. A. Setia, "Optimasi Operasi Pembangkit Listrik Tenaga Air ( PLTA ) Menggunakan Linear Programming dengan Batasan Ketersediaan Air," Optimasi Operasi 
Pembangkit List. Tenaga Air Menggunakan Linear Program. dengan Batas Ketersediaan Air, vol. 9, no. 2, pp. 1-6, 2013.

[3] E. Fahmivalecom, D. Magister, M. Fakultas, D. Magister, M. Fakultas, and B. Universitas, “(PLTA) DEPARTMENT MAINTENANCE \& UTILITIES PT . VALE INDONESIA OPERATIONAL STRATEGY HYDROELECTRIC POWER PLANT MAINTENANCE \& UTILITIES DEPARTMENT OF PT . VALE Fahmi Mahasiswa Magister Manajemen Fakultas Ekonomi dan bisnis Universitas Hasanuddin Jusni Duni," Strateg. Oper. Pembangkit List. Tenaga Air Dep. Maint. Util. Pt. Val. Indones., vol. 14, no. 1, pp. 27-34, 2017.

[4] P. Assignment, "PLN Corporate University," Pembangkit Termal 1 (PLTU), Ed. 1, pp. 7-13, 2015.

[5] J. Teknik and M. Untirta, "Volume II Nomor 1, April 2016 (Yeny Pusvyta)," vol. II, no. April, pp. 43-54, 2016. 